\title{
Supervisory feedback in the principal evaluation process
}

\author{
Ahmed M. Alkaabi ${ }^{1}$, Suhair Ali Almaamari ${ }^{2}$ \\ ${ }^{1}$ Foundations of Education Department, United Arab Emirates University, United Arab Emirates \\ ${ }^{2}$ English Language Trainer, Ministry of Education, Oman
}

\begin{tabular}{l}
\hline \hline Article Info \\
\hline Article history: \\
Received Apr 3, 2020 \\
Revised Jun 10, 2020 \\
Accepted Jul 23, 2020 \\
\hline
\end{tabular}

Keywords:

Feedback

Formative evaluation

Principal evaluation

School leaders

Supervisors

\begin{abstract}
The purpose of this qualitative study is to understand how school principals perceive their supervisors' feedback in the formative principal evaluation process. It spotlights the benefits of supervisors giving effective feedback to school principals as a key component in formative evaluations. In addition, it uses a qualitative case-study design situated within the context of the Al-Ain school district, which is supervised by the Abu Dhabi Education Council in the United Arab Emirates. The data was collected using several data collection methods, namely interviews, documents, and field notes. Six school principals participated in the study, and a thematic analysis of their comments and other information that they provided yielded four themes that reflected the quality of feedback they received: (1) feedback in absentia, (2) superficial or irrelevant feedback, (3) negative or judgmental feedback, and (4) constructive and individualized feedback. The evidence concludes that feedback aimed at improving the leadership practices of principals is limited, and there is no embedded professional learning dialogue wherein such feedback exists. This study adds to the body of leadership literature and sets forth implications for enhancing and redesigning feedback delivery in the formative evaluation process to improve principals' practices and support their professional growth.
\end{abstract}

This is an open access article under the CC BY-SA license.

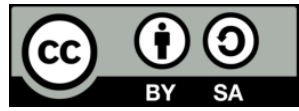

\section{Corresponding Author:}

Ahmed Mohammed Alkaabi,

Foundations of Education Department,

United Arab Emirates University,

Sheik Khalifa Bin Zayed St, Al-Ain City, Abu Dhabi, United Arab Emirates.

Email: ahmed.alkaabi@uaeu.ac.ae

\section{INTRODUCTION}

Principal evaluation has become the forefront of discussion and educational agenda in countries around the globe. This trend is due largely to longitudinal research documenting school principals having a significant, albeit indirect, effect on student learning within the confines of the classroom [1,2]. Measuring the exact effectiveness of principal performance is a challenging task with which educators in the field of education grapple. Stronge [3] stressed the urgent need to establish carefully designed evaluation systems capable of capturing leadership performance with unerring accuracy and helping principals improve their leadership skills. Implementing effective principal evaluations is especially critical given the drastic, emerging role-changes that 21 st-century principals face. Where once they were simply school managers, they ever-increasingly fill the roles of instructional leaders and change agents responsible for raising funds, supervising teachers, overseeing curricula, analyzing data, mediating with the community, and spearheading change [4]. The overwhelming nature of these new roles has garnered long-overdue attention regarding the value of school leaders and the need for effective evaluation that enables them to meet expectations. 
Despite the call to implement principal evaluation systems, existing studies conducted in the United States and other countries revealed that significant deficiencies were present in most principal evaluation systems. Too often, these flaws directly relate to the delivery of unclear and ineffective feedback from supervisors to their principals in the formative evaluation process [5, 6]. Additionally, the research findings showcased administrators who rarely received constructive or specific feedback that targeted their individual needs or acted as a guide to further their capacities [6, 7]. Supervisors who do not spend adequate time visiting, observing, and assessing the performance of their principals' risk jeopardizing the progress of schools and school districts [8]. Moreover, when principal supervisors cannot effectively gauge the performance of their principals, they are unlikely to be able to identify any significant deficiencies in their practices. Furthermore, when such insufficiencies are not addressed, there is little chance that principals will be able to improve their performance or that of their schools [9]. Yet, even when insufficiencies are addressed, providing support and continuous feedback is more than just saying "everything is great" or "you need to improve" [10]. Timely, specific, concise, and future-oriented feedback that assists principals in developing an actionable plan for growth and development is needed [11, 12].

Reliable, well-rounded, and dedicated supervisors are required throughout the entire evaluation process to take full advantage of the benefits of sound principal evaluation [7, 13]. Kimball, Milanowski, and McKinney [14] asserted that principal evaluation systems demand more than mere submission or obedience to professional standards, rubrics, and instruments; they require dynamic supervisor-principal pairing and dialogue for the fulfillment of the objectives of evaluation and supervision. To use principal evaluation as a learning tool for growth and development, principal supervisors should consistently provide support and meaningful feedback, establish and convey the principles of adult learning, facilitate and engage group learning processes, and promote and cultivate a culture grounded in transparency and continuous learning [15].

Zepeda et al. [16] illuminated one prerequisite to substantial principal growth and improvement: a supportive structure to encapsulate formative, ongoing, developmental, and differentiated supervisory approaches. A supportive structure leads to summative evaluations from which new professional goals can be established. This assertion emphasizes that supervision and evaluation are intertwined in a cyclical system whereby the formative process furnishes the way and informs the summative evaluation by articulating the most-needed goals for development and principal growth [17]. In essence, school leadership evaluation is a multi-year roadmap for professional development, long-term growth, meaningful dialogue, continuous reflection, and the attainment of leadership skills.

The purpose of this study is to understand how school principals perceive and experience the feedback provided by their supervisors (i.e., cluster managers) in the formative principal evaluation process in the United Arab Emirates (UAE) - specifically in the city of Al-Ain. This study spotlights the value of such feedback as a key component in the formative evaluation and a mandatory responsibility of principal supervisors. While the literature is replete with studies on teacher supervision, research on leadership supervision (i.e., principal supervision) has received far less attention [16, 18], with no such research in the UAE. For instance, one element of the principal evaluation that has not been researched sufficiently in the current literature is the effectiveness of supervisory feedback provided by supervisors and the extent to which that feedback nourishes the learning process and expands the leadership capacity of school leaders. Additionally, within the realm of supervisory feedback, there is little to no literature documenting how supervisors deliver feedback and how it influences the school principals they supervise. Narrowing in even further, there is no single study in the UAE on the perceptions of Emirate principals regarding the effectiveness of the feedback provided by their supervisors. This study attempts to fill that gap.

The present study addresses the following question: How do school principals perceive and experience the feedback delivered by their assigned supervisors in the formative evaluation process? The answers to this research question unveil not only disseminated practices pertaining to the quality of feedback provided to principals, but also how supervisors can deliver valuable, differentiated, and actionable feedback to ensure their principals are improving their practices as instructional leaders. The findings of this study will help supervisors open their eyes in crafting feedback in a manner that boosts positive behavioral changes in principals.

\section{RESEARCH METHOD}

This study incorporated a qualitative research design, which is effective in answering "what," "why," and "how" questions [19]. Qualitative inquiry, specifically, accelerates an informative and interpretive understanding of the social world of research participants by looking deeply into the sense they make about their social and material circumstances, experiences, perspectives, and histories [20]. Qualitative inquiry allowed the researcher of this study to examine how Al-Ain school principals perceived 
their supervisors' feedback during the formative evaluation process. The responses gathered from principals detailed in-depth descriptions of the phenomenon under investigation.

Given its potential for exploring specific phenomena through more than one lens and using multiple data sources [21, 22], this qualitative study was broadly framed within the research methodology of a case study. The study was situated in the context of the Al-Ain school district during 2018, which is supervised by Abu Dhabi Education Council (ADEC). The case-study design helped the researcher gain a deeper understanding of the effectiveness of feedback provided in the formative evaluation process. Yin [23] pointed out that case studies offer the advantage of addressing how and why investigators are "asked about a contemporary set of events over which the investigator has little or no control." The benefits of the case study can be maximized by using a multi-case design - which this study employed-because it results in more empirically rich and holistic information regarding a specific phenomenon [23].

One critical step in forming a solid case study is defining the objects of the study [22], and the researcher identified a basic unit of analysis using a case-study approach to that end. According to Yin [23], the unit of analysis upon which the case studies are based is determined by the research questions of the study. With that in mind, the multi-case design included a total number of six cases: three male and three female principals. This study relied on several data collection methods to obtain participants' feedback on the formative evaluation process, including face-to-face interviews, documents, and field notes for triangulation and data saturation purposes. The researcher used interviews as the primary data collection method to determine what quality of feedback was given to principals and whether it facilitated their growth and development [24].

\subsection{Research participants}

Each principal participated in an in-depth, two-hour, face-to-face interview with the aim of obtaining data about their unique perspectives - specifically, their experiences as recipients of feedback in the formative evaluation process. The participants were recruited using the purposeful sampling technique, which, in this case, entailed selecting qualified individuals who were well-versed and experienced with the phenomenon of interest. The researcher also used a requirement checklist to select candidates for the sample [20], which primarily consisted of the following three items: currently experiencing the evaluation process established by ADEC, having a supervisor tasked with evaluative and supervisory roles, and being willing to share and contribute in reflective conversation about their personal practices and experiences. Table 1 shows the demographic profile of the research participants.

Table 1. Demographic profile of the research participants

\begin{tabular}{cccc}
\hline Participants & Sex & Years of experience & School level \\
\hline Ms. Aysha & Female & 18 & Primary \\
Ms. Hind & Female & 23 & Middle \\
Ms. Njoud & Female & 17 & High School \\
Mr. Mazen & Male & 18 & Primary \\
Mr. Khaled & Male & 16 & Middle \\
Mr. Fahad & Male & 14 & High School \\
\hline
\end{tabular}

The researcher contacted the ADEC research office to obtain approval to conduct this study, enter public schools, and conduct interviews. Then, after receiving a list of potential principal participants from the Al-Ain school district, the researcher emailed each of them with brief background information on the study and expectations of participants who had a desire to be involved. As participants met the criteria for participation and showed a strong desire to participate via their email responses, the researcher detailed the research project and sent each an electronic copy of a consent letter for them to review and sign as confirmation of their involvement in the study.

Prior to each interview, the researcher arranged a time and place that worked around each principal's schedule. At the beginning of the interview, the researcher provided the participants with a brief introduction about himself, the purpose of the interview, and the goals of the same. He recorded all interviews electronically using an IC Recorder and transcribed them verbatim. He advised them to speak in the language with which they felt the most comfortable and able to express their views and insights clearly. Additionally, to maintain confidentiality, the researcher removed all identifying information from the interview transcripts, using pseudonyms in place of names.

\subsection{Data analysis}

The researcher employed a thematic analysis to identify, analyze, and report the patterns (themes) within the data sets gathered from the interview transcripts [25]. As articulated by Braun and Clarke [26], 
thematic analysis is used to order qualitive data and unravel the twisted threads of data to generate emerging themes from which proper interpretation can then address the purpose(s) of the study and answer the research question(s). However, before the data analysis process, the researcher familiarized himself with the data by reading each transcript several times to become acquainted with the data and gain a real sense of it. He generated multiple codes from each interview transcript that illustrated similarities and differences among the narratives and experiences. Afterwards, he carefully grouped the codes into their respective categories, adding verbal illustrations from participants and using direct quotes from the interviews for corroboration and verification.

In assessing and ensuring credibility, the researcher utilized triangulation and member-checking. First, he triangulated and compared the data collected through interviews, documents, and field notes, examining the consistency of findings generated by different data-collection methods and the confluence of data sources from within the same methods at different points in time [27, 28]. Then, he used memberchecking by asking participants to review the interview transcriptions to ensure their perceptions were represented accurately. Throughout this entire process, the researcher continually observed self-reflexivityas Chiseri-Strater [29] recommended-by acknowledging how his identity, experience, knowledge, and relationships may have influenced the research. According to Merriam [30], reflexivity statements unearth the identity of the researcher and enable readers to ponder upon and understand their interpretations of the data.

\section{RESULTS AND DISCUSSION}

This study explored school principals' perceptions and experiences with the feedback provided by their supervisors in the formative evaluation process by using in-depth interviews, documents, and field notes. The findings illuminated four themes that reflect the quality of supervisor-principal feedback: (1) feedback in absentia, (2) superficial or irrelevant feedback, (3) negative or judgmental feedback, and (4) constructive and individualized feedback. It is important to note that there were no significant differences between male and female principals regarding their perceptions of supervisory feedback-most had undergone similar experiences that collectively shaped the themes. These similarities could have been due to some participants having the same supervisor at some point in their careers. Only the surrounding circumstances and examples they narrated were different.

\subsection{Theme one: Feedback in absentia}

Within this theme, principals in the study explained that feedback was absent because their assigned supervisors did not show up nor provide any feedback throughout the formative evaluation process. Ms. Njoud, for instance, wondered how feedback embedded in supervision could be effective if supervisors self-excluded themselves from the process. Principals who take long absences can negatively impact evaluation. Parallelly, Mr. Mazen explained, "Supervisors who were not in the building could not effectively capture snapshots of the principals' work. [Therefore, they] were unable to review leadership performance to provide appropriate guidance and supportive feedback." Mr. Fahad also shared his experience with some of his former supervisors who provided no feedback during the evaluation process:

They rarely visit the school, [and] ask this question: 'Is everything alright in the school?' and right-off left the school without saying a word after I replied, 'Yes, everything is fine.' I will not hear from them...until the end of the summative evaluation.

As articulated by the participants, some supervisors' negligence was obvious during the formative evaluation process. This finding was consistent with the results of Corcoran et al. [31], who found that supervisors rarely visited schools to observe, monitor, and capture the work of their principals or provide feedback and support to elevate their leadership performance. All participants in the current study emphasized that they would have had greater opportunities to learn if the formative evaluation process had included ongoing feedback that allowed them to improve their leadership capacities.

\subsection{Theme two: Superficial and irrelevant feedback}

In the second theme, the supervisors focused their feedback on irrelevant issues. This superficial feedback hardly touched on the critical topics of instructional leadership. Ms. Aysha referred to the feedback she received from her supervisors throughout the entire evaluation process as "simplistic" and deprived of depth and quality, yet laden with positive remarks. Another principal, Ms. Hind, welcomed positive comments, such as "Good work," "Keep going," or "Well done" as indicators of approval, yet they did not steer her to improve nor refine her leadership practices. She sought specific and detailed feedback that 
could provide direction for her leadership growth, but was left to guess for herself. Yet another principal, Mr. Khaled, received no feedback throughout the evaluation process over eight years with three different supervisors.

In many cases, the principals felt that feedback intended to improve their leadership practices was limited and that there were little to no strategically structured or meaningful professional learning dialogues that encouraged their continual engagement in reflective practices. This finding mirrored the results of multiple studies that revealed principal evaluations failed to provide specific feedback targeting individual needs, capturing strengths and weaknesses in performance, or guiding the development of principal leadership capacities $[5,6,32]$. Participating principals espoused the belief that their supervisors "should know better" and be able to "provide the support" they needed by delivering "constructive feedback," offering "effective guidance," and providing "quality supervision" to aid them in exceling in their challenging positions.

\subsection{Theme three: Negative and judgmental feedback}

The third theme covered principals who described negative and judgmental feedback that was destructive to the supervisory relationship and the evaluation process. Ms. Njoud, for example, described her feedback experience as being "invasive," "judgmental," and "directive." She elaborated, "[The supervisors] would give me judgmental and directive feedback. They would tell me 'You are wrong,' and then say what to do and what not to do with no deliberate thought given to the situation." In similar fashion, Mr. Mazen experienced negative feedback from supervisors that made him feel distant and less productive. Negative feedback can inflate an already stressful situation by creating rather intense and distant relationships, which ultimately causes a decrease in principals' ability to function effectively. For the most part, principals' disappointment in their supervisors' attitudes towards feedback was easily discernible as they described their formative evaluations.

Principals who were mistreated by negative feedback felt trapped by coercion and intimidation practices. The resulting sense of mistrust created fallouts and a breakdown of the supervisory relationship, which halted contribution, productivity, and willingness to participate in the evaluation process. These negative effects created an ominous tone, wasted valuable learning experiences, and transformed the evaluation into a meaningless exercise. The findings of this theme echoed the study of Parylo et al. [17], whose principal participants felt both hurt and upset as they received negative feedback from their supervisors. The primary difference between the findings of the present study and those of Parylo et al. [17] was that the participants of the latter were not resistant to negative feedback; rather, they made behavioral changes accordingly and used the feedback to become more aware of things they had not previously realized in themselves. In the present study, however, the principals felt confined to a "bubble" that woefully drained their energy and destabilized their ability to function. For them, negative feedback was a vicious, energyabsorbing mass that forced them to avoid seeking outside advice on performance improvement. For the benefit of both the individual and the team, participants suggested that supervisors realize the worth of feedback as a guiding tool in supporting leadership development.

\subsection{Theme four: Constructive and individualized feedback}

The final and least-occurring theme was constructive feedback. Principals indicated that constructive feedback was provided by only a few skilled supervisors who gave valuable and detailed guidance that provided direction for their leadership growth. Some principals mentioned that their assigned supervisors provided constructive and detailed feedback in one of their eight years of evaluation experience. Nonetheless, the positive experience was short-lived because supervisors rotated or transferred to other locations the following year. Fahad shared his experience in receiving worthwhile feedback:

[The supervisor] scheduled a meeting. In the meeting, we walked through several things...took time talking about what I would have done wrong...how I would have done things differently. The session was great, helpful. It made me reflect on things, realize things, [and] feel comfortable. It helped clarify how to focus my intentions and how to move up to the next level-to select goals and the right actions to do so.

Participating principals concluded that when feedback and guidance was delivered in a constructive, detailed manner, they were less likely to become confused or feel lost during the formative evaluation process. Additionally, they were more likely to share their thoughts, formulate properly aligned professional goals, and take corrective action. Mr. Khaled agreed that having set, individualized feedback sessions established the performance trajectory to be explored, discussed, and reflected upon-all of which helped him focus his "intentions [on] how to move up to the next level." Ms. Hind, on a similar note, worked with 
six supervisors, and one gave her constructive and individualized feedback. Unfortunately, she only worked with that supervisor for three months, but she appreciated the carefully crafted supervision experience and feedback sessions. She reflected on her experience:

This interim supervisor was different. She gave constructive feedback that encouraged behavioral change in practice. She spent sacred time to see my observing skills in teachers' classrooms, facilitated our forthcoming discussions through the use of reflective questioning, and collected data from stakeholders about the school. Her feedback touches every single work I do in the school.

The positive feedback that a few principals in the study experienced mirrored the findings of Hvidston et al. [33], who proposed that in order for supervision to be effective in the evaluation process, it needed to include specific feedback that pertained to the instructional practices of principals and offered reflective learning opportunities by which they could consider their leadership practices. Parylo et al. [17] contributed to this by urging evaluators to make principal evaluation "a continuous, transparent process" that promoted professional "dialogue," reinforced mutual "trust and respect," and welcomed "constructive feedback." Each of these facilitate ongoing development and provide valuable insights for helping principals become more effective leaders of their schools in this challenging and demanding era.

\section{CONCLUSION}

This study has shed light on effective feedback as a key component in the formative evaluation that expands principals' learning and boosts their leadership development. The findings of the thematic analysis yielded four themes that reflect the quality of feedback: (1) feedback in absentia, (2) superficial or irrelevant feedback, (3) negative or judgmental feedback, and (4) constructive and individualized feedback. As this study has showcased, feedback aimed at improving the leadership practices of principals is often limited, and there is little purposeful, professional feedback embedded in the principal evaluation process. Negative or judgmental feedback is present too often and serves as a fatal arrow that not only destroys supervisory relationships, but also creates an ominous, growth-stunted atmosphere within the formative evaluation. Only a few of the principals who participated in this study cherished their experiences with supervisory feedback. Even so, nearly all of them considered feedback to be a vital component of the evaluation process.

The author recommends that supervisors focus their supervisory feedback sessions around principals' specific areas of need to help them explore, discuss, and reflect on how they might improve in those areas. Furthermore, implementing professional development for supervisors themselves would bolster the core roles of coaching, supervision, and differentiated support. Well-structured professional development would also allow principal supervisors to develop additional competencies and help them grow from novices to autonomous professionals. It would nourish educational learning, propagate best practices, foster professional growth, instill supervisory skills, improve attitudes, and broaden the scope of knowledge among principal supervisors.

Professional development can help supervisors provide feedback that is timely, specific, actionable, differentiated, and future-oriented, all of which enable principals to move forward and grow as effective instructional leaders. Future studies could add to this one by conducting quantitative research on supervisorprincipal feedback, including a higher number of principals, and interviewing principal supervisors across all emirates to have more generalizable results. There are also many angles to principal evaluation that warrant further investigation, such as the tug-of-war between the formative and summative evaluations, confrontation in the summative evaluation session, self-evaluation, the portfolio, evaluation instruments and metrics, multisource assessments, and the roles of supervisors. Carefully researching these areas and providing additional solutions to inherent problems within the domains of evaluation and feedback would enlighten researchers and professionals alike and promote more effective evaluation practices.

\section{ACKNOWLEDGEMENTS}

I appreciate the cooperation and approval of the Abu Dhabi Education Council Research Center in conducting this study and entering schools without any trouble. I also extend my gratitude to the school principals who demonstrated a strong desire and willingness to participate and share their experiences with the phenomenon under study. 


\section{REFERENCES}

[1] K. Leithwood, K. S. Louis, S. Anderson, and K. Wahlstrom, "How leadership influences student learning: Review of research learning from leadership project," The Wallace Foundation. New York, USA, Tech. Rep., pp. 1-88, 2004. [Online]. Available: https://www.wallacefoundation.org

[2] The Wallace Foundation, "The school principal as leader: Guiding schools to better teaching and learning," New York, USA, Tech. Rep., pp. 1-25, 2013. [Online]. Available: https://www.wallacefoundation.org.

[3] J. H. Stronge, "Principal evaluation from the ground up," Educational Leadership, vol. 70, no. 7, pp. 60-65, 2013.

[4] S. J. Zepeda, The principal as instructional leader: A handbook for supervisors (3rd ed). New York, NY: Routledge, 2013.

[5] A. H. Normore, "Leadership success in schools: Planning, recruitment, and socialization," International Electronic Journal for Leadership in Learning, vol. 8, no. 10, pp. 1-22, 2004.

[6] B. S. Portin, S. Feldman, and M. S. Knapp, "Purposes, uses, and practices of leadership assessment in education," University of Washington, USA, Tech. Rep., pp. 1-50, 2006. [Online]. Available: https://www.education.uw.edu/ctp/sites/default/files/ctpmail/PDFs/LAssess-Oct25.pdf

[7] E. Goldring, X. Cravens, J. Murphy, A. Porter, S. Elliott, and B. Carson, "The Evaluation of principals: What and how do sates and urban districts assess leadership?" The Elementary School Journal, vol. 110, no. 1, pp. 19-39, 2009.

[8] M. I. Honig, "District central office leadership as teaching: How central office administrators support principals' development as instructional leaders," Educational Administration Quarterly, vol. 48, no. 4, pp. 733-774, 2012.

[9] J. Green, Evaluating principals: Issues and practices. Bloomington, IN: Phi Delta, 2004.

[10] A. Saltzman, "Stories from the field: The power of principal supervisors," The Wallace Foundation, Washington, D.C, Tech. Rep., pp. 1-13, 2016. [Online]. Available: https://www.wallacefoundation.org

[11] E. B. Goldring, J. A. Grissom, M. Rubin, L. K. Rogers, M. Neel, and M. A. Clark, "A new role emerges for principal supervisors: Evidence from six districts in the principal supervisor initiative," The Wallace Foundation, New York, USA, Tech. Rep. pp. 1-64, 2018. [Online]. Available: https://www.wallacefoundation.org

[12] S. Syed, "Beyond buses, boilers, and books," The Learning Professional, vol. 35, no. 5, pp. 46-49, Oct 2014.

[13] S. J. Zepeda and P. D. Lanoue, "Conversation walks: Improving instructional leadership," Association for Supervision and Curriculum Development, vol. 74, no. 8, pp. 58-61, May 2017.

[14] S. M. Kimball, A. Milanowski, and S. A. McKinney, "Assessing the promise of standards-based performance evaluation for principals: Results from a randomized trial," Leadership and Policy in Schools, vol. 8, no. 3, pp. 233-263, 2009.

[15] D. Micheaux and J. Parvin, "Principal evaluation as a tool for growth," The Learning Professional, vol. 39, no. 2, pp. 52-55, Apr 2018.

[16] S. J. Zepeda, P. D. Lanoue, W. G. Creel, and N. F. Price, "Supervising and evaluating principals-The new work of superintendents and central office personnel," in Supervision: New perspectives for theory and practice, J. Glanz and S. J. Zepeda, Eds. Lanham, MD: Rowman and Littlefield, pp. 63-79, 2016.

[17] O. Parylo, S. J. Zepeda, and E. Bengtson, "Principals' experiences of being evaluated: A phenomenological study," Educational Assessment, Evaluation and Accountability, vol. 24, no. 3, pp. 215-238, 2012

[18] S. J. Zepeda, P. D. Lanoue, N. F. Price, and A. M. Jimenez, "Principal evaluation-Linking individual and buildinglevel progress: Making the connections and embracing the tensions," School Leadership and Management, vol. 34, no. 4, pp. 324-351, 2014.

[19] J. Ritchie, J. Lewis, C. Nicholls, and R. Ormston, Qualitative research practice: A guide for social science students and researchers. Los Angeles, CA: SAGE, 2014.

[20] M. Q. Patton, Qualitative research and evaluation methods. Thousand Oaks, CA: SAGE, 2015.

[21] H. Simon, Case study research in practice. Los Angeles, CA: SAGE, 2009.

[22] S. B. Merriam, Qualitative research and case study applications in education (2nd ed). San Francisco, CA: JosseyBass, 1998.

[23] R. K. Yin, Case study research: Design and methods (5th ed). Los Angeles, CA: SAGE, 2014.

[24] I. Seidman, Interviewing as qualitative research: A guide for researchers in education and the social science. New York, NY: Teachers College Press, 2012.

[25] M. Maguire and B. Delahunt, "Doing a thematic analysis: A practical, step-by-step guide for learning and teaching scholars," All Ireland Journal of Teaching and Learning in Higher Education, vol. 8, no. 3, pp. 3351-33514, 2017.

[26] V. Braun and V. Clarke, "Using thematic analysis in psychology," Qualitative Research in Psychology, vol. 3, no. 2, pp. 77-101, 2006.

[27] N. K. Denzin, Sociological methods. New York, NY: McGraw-Hill, 1978.

[28] Y. S. Lincoln and E. Guba, Naturalistic inquiry. Newbury, CA: SAGE, 1985.

[29] E. Chiseri-Strater, "Turning in upon ourselves: Positionality, subjectivity, and reflexivity in case study and ethnographic research," in Ethics and representation in qualitative studies of literacy, P. Mortensen \& G. E. Kirsch, Eds. Champaign-Urbana, IL: National Council of Teachers of English, pp. 63-79, 1996.

[30] S. B. Merriam, Qualitative research: A guide to design and implementation. San Francisco, CA: Jossey-Bass, 2009.

[31] A. Corcoran, M. Casserly, R. Price-Baugh, D. Walston, R. Hall, and C. Simon, "Rethinking leadership: The changing role of principal supervisors," The Wallace Foundation. Washington, D.C, Tech. Rep., pp. 1-83, 2013.

[32] D. B. Reeves, Assessing educational leaders: Evaluating performance for improved individual and organizational effectiveness, (2nd ed). Thousand Oaks, CA: Corwin Press, 2013.

[33] D. J. Hvidston, C. A. McKim, and I. M. Mette, "Principals' supervision and evaluation cycles: Perspectives from principals,” Education Leadership Review, vol. 17, no. 1, pp. 100-113, 2016. 